\title{
Investigation of stem cells in adult and prepubertal mouse ovaries
}

\author{
Yashar Esmaeilian $^{1 *}$, Bala Gur Dedeoglu ${ }^{1}$, Arzu Atalay ${ }^{1}$, Esra Erdemli $^{2}$ \\ ${ }^{1}$ Central Lab of Biotechnology Institute, University of Ankara, Ankara, Turkey \\ ${ }^{2}$ Department of Histology and Embryology, School of Medicine, University of Ankara, Ankara, Turkey \\ Email: *yashares@ankara.edu.tr
}

Received 11 August 2012; revised 25 September 2012; accepted 14 October 2012

\begin{abstract}
The possible presence of oocyte and granulosa cells originated from stem cells in the adult mammalian ovaries was claimed by some studies which will lead to major changes in reproductive biology and infertility treatments. Purpose of this research is to investigate the possible existence and the location of the potential stem cells in mouse ovaries. In this study, the ovaries from 2-week (pre-puberty) and 8-week (adult) old BALB-C mice were used. For the investigation of the presence of possible stem cells, the expression profiles of three well known stem cell markers, Oct-4, Nanog and Sox 2 were determined in the ovaries of two different age groups by real time quantitative RT-PCR (qRT-PCR). Protein expression levels and their localization in the ovary cells were immunohistochemically evaluated on fresh-frozen ovary tissue sections by using monoclonal antibodies specific to Sox2, Nanog and Oct-4. The gene expression levels of Oct-4 and Nanog were found to be significantly differentiated between 2-week old and 8-week old mice whereas no significant difference was observed in the expression level of Sox2 between two age groups. Immunohistochemistry results showed the presence of both Sox 2 and Oct-4 protein in the cytoplasm of ovarian epithelial cells, granulosa cells, oocytes and theca cells. Nanog protein was observed only in the nucleus of the oocytes and furthermore the expression of Nanog was higher in eight weeks old samples compared to two weeks old ones according to qRT-PCR results. These results suggest for the first time that Nanog protein is expressed both in adult and pre-puberty mouse ovaries and locate at the nucleus of the oocytes and to the best of our knowledge this is the first study that shows the differential expression of Oct-4, Nanog and Sox2 in pre-puberty and adult mouse ovaries by qRT-PCR. Collectively, our results may suggest that both pre-puberty and
\end{abstract}

"Corresponding author. adult mice ovaries accommodate cells carrying stem cell features.

Keywords: Ovarian Stem Cell (OSC); Oct-4; Nanog; Sox2; Real Time-PCR; Immunohistochemical Staining

\section{INTRODUCTION}

According to the results of extensive research on the reproductive biology of most mammalian females, all germ cells at the end of fetal development enters meiosis, since after birth ovary contain limited number of oocytes. If this resource is lost due to sickness or injury of ovary, there is no possibility of renewal. However, the new reports have opened this perspective to discuss.

Johnson and colleagues (2004) demonstrate that juvenile and adult mouse ovaries contain mitotically active germ cells. By manipulation of prepubertal female mice with the mitotic germ-cell toxicant busulphan eradicates the primordial follicle source by early adulthood without stimulating atresia. Additionally, they manifest cells expressing the meiotic entry marker synaptonemal complex protein 3 (SCP3) in juvenile and adult mouse ovaries. Wild-type ovaries grafted into transgenic female mice with omnipresent expression of green fluorescent protein (GFP) become penetrated with GFP-positive germ cells that form follicles [1].

In 2005, a research about the possibility of differentiation of oocytes and granulose cells was done on cultures that derived from adult human ovaries. Cells were collected from the surface of ovaries and cultured for $5-6$ days with or without estrogenic inducement phenol red $(\mathrm{PhR})$. The ovarian surface epithelium (OSE) cells that cultured in the presence of $\mathrm{PhR}$ differentiated into small (15 micron) cells of granulosa phenotype, neural, epithetlial, and mesenchymal type cells. In contrast, OSE cells that cultured accompanied by PhR differentiated immediately into large (180 micron) cells of the oocyte phenotype [2].

A study was done on 25 women (20 postmenopausal and 5 with premature ovarian failure) with the aim to 
isolate putative ovarian stem cells (OSCs) from the OSE layer. Small round cells with a bubble-like structure and $2-4 \mu \mathrm{m}$ diameters were isolated from the material collected by OSE scraping. These cells expressed early embryonic developmental markers such as SSEA-4 (StageSpecific Embryonic Antigen-4) and Oct-4 (OctamerBinding Transcription Factor 4), Sox-2, Nanog, and c-kit transcription markers, and they show noticeable c-kit immunohistochemical staining. In the culture of OSE cell, oocyte-like cells developed, reached up to $95 \mu \mathrm{m}$ diameter and expressed Oct-4A, Oct-4B, c-kit, VASA, and ZP2 (Zona Pellucida Sperm-Binding Protein 2) transcription markers, same as early oocytes. Consequently, the observed cells with the expression of embryonic stem cell markers are suggested to represent the adult ovarian stem cells [3].

Honda and colleagues (2007) have isolated putative thecal stem cells with the capacity of self-renewal and differentiation in vivo and in vitro. These cells were stimulated to differentiate into early precursors and steroidogenic cells. These cells expressed expected genes and morphological markers and also later secreted androstenedione [4].

According to the study on normal adult human ovaries, active meiosis, neo-oogenesis and germline stem cells (GSCs) are nonexistent. Compared to fetal ovary and adult testis controls, there is no early meiotic-specific or oogenesis-associated mRNAs for SCP1 (synaptonemal complex protein 1), PRDM9, SPO11, TERT (Telomerase Reverse Transcriptase) and NOBOX were noticeable in adult human ovaries using RT-PCR. These results were supported by the absence of early meiocytes and proliferating germ cells in adult human ovarian investigated with markers for meiosis (synaptonemal complex protein 3 or SCP3), oogonium (c-Kit, OCT3/4) and cell cycle progression (Ki-67, PCNA), compared to fetal ovary controls [5].

Oct-4, Nanog, and Sox 2 genes are located at the center of transcriptional regulatory hierarchy and are used as stem cells determinants [6-8]. These genes by activating themselves and key components of signaling pathways and by silencing genes of developmental process provide the self-renewal and pluripotential properties of stem cells [9]. Mouse and human embryonic stem cell (ESC) studies have demonstrated that Oct-4 and Sox 2 bind to Nanog promoter [10]. Sox2 is able to synergistically interact with Oct3/4 in vitro to activate Oct-Sox enhancers, which regulate the expression of pluripotent stem cellspecific genes, including Oct3/4, Nanog and Sox2 itself [11].

Consequently, in reproductive biology, presence of postnatal ovarian stem cells is still a controversy issue and some studies have rejected the presence of these cells. So we decided to study the possible existence of mouse ovarian stem cells by using pluripotent stem cells markers (Oct-4, Nanog and Sox2) at gene and protein levels.

\section{MATERIALS AND METHODS}

\subsection{Animals}

A total of 48 ovaries from 2-week (pre-puberty) and 8-week (adult) old BALB-C mice were collected by laparoscopy. The mice were obtained from the animal facility of Ankara University, Faculty of Medicine. This study was done by Ankara University animal experiments ethics committee approval No: 2009-186.

\subsection{RNA Extraction and cDNA Synthesis}

Total RNA was extracted from each ovary sample using TRIzol reagent (Invitrogen, USA) according to the manufacturer's instructions. The concentration of the isolated RNA and the ratio of absorbance at $260 \mathrm{~nm}$ to $280 \mathrm{~nm}$ were measured with the NanoDrop ND-1000 spectrophotometer (NanoDrop Technologies, Montchanin, DE, USA). $1 \mu \mathrm{g}$ of total RNA was used for reverse transcription using 1st Strand cDNA Synthesis Kit for RTPCR (AMV) (Roche, Germany) following the manufacturer's recommended protocol. The reverse transcriptase was mixed with $2 \mu \mathrm{L}$ Oligo(dT) 15 primer (5'-TTT TTT TTT TTT TTT-3') according to the manufacturer's instructions (Roche), $4 \mu \mathrm{L}(25 \mathrm{mM}) \mathrm{MgCl}_{2}, 2 \mu \mathrm{L}$ Deoxynucleotide Mix, $2 \mu \mathrm{L}$ 10X Reaction Buffer and $20 \mathrm{U}$ RNase Inhibitor to a total volume of $20 \mu \mathrm{L}$. First strand cDNA was synthesized for $60 \mathrm{~min}$ at $37^{\circ} \mathrm{C}$. The reaction was stopped by incubation at $70^{\circ} \mathrm{C}$ for $10 \mathrm{~min}$. Products were stored at $-20^{\circ} \mathrm{C}$ to be used as a PCR template for further experiments.

\subsection{Real Time-PCR}

Real-Time qRT-PCR analysis was performed using gene-specific primer pairs (listed in Table 1). Oct-4, Nanog and glyceraldehydes-3-phosphate dehydrogenase (GAPDH) primers were designed by Primer exe program and Sox 2 primer sequences were obtained from an article [12]. The primers were designed to include intronic sequences between the forward and reverse pair or designed from exon-exon boundaries to avoid genomic DNA contamination if any remained in the RNA samples. The sequences of the gene-specific primers were put into the Blast search to find out their specificities. None of the primer pairs showed significant homology to other sequences in the genome. The GAPDH gene was amplified for each sample, and used as a loading control. Real time RT-PCR analysis was performed on Roche LighteCycler 480 using the LightCycler 480 SYBR I Master mix (Roche, Germany). The amplification mixtures contained $1 \mu \mathrm{L}$ cDNA template, $10 \mu \mathrm{L}$ SYBR Green PCR Master Mix Buffer (2X), and 10 pmol of forward and 
Table 1. Primer sequence, length of primers, product size and function of primers used in this study (listed 5' to 3' end).

\begin{tabular}{clccc}
\hline Gene & Primer & bp & Product Size & Function \\
\hline \multirow{2}{*}{ Oct-4 } & $\begin{array}{l}\text { Forward: AGGAAGCCGACAACAATGAG } \\
\text { Reverse: CTGATTGGCGATGTGAGTGA }\end{array}$ & 20 & 173 & Marker \\
Nanog & $\begin{array}{l}\text { Forward: AGCAGATGCAAGAACTCTCC } \\
\text { Reverse: CAGATGCGTTCACCAGATAG }\end{array}$ & 20 & 207 & Marker \\
\multirow{2}{*}{ Sox2 } & $\begin{array}{l}\text { Forward: TAGAGCTAGACTCCGGGCGATGA } \\
\text { Reverse: TTGCCTTAAACAAGACCACGAAA }\end{array}$ & 23 & 297 & Marker \\
GAPDH & $\begin{array}{l}\text { Forward: ATGGTGAAGGTCGGTGTGAA } \\
\text { Reverse: CCTTGACTGTGCCGTTGAAT }\end{array}$ & 20 & 178 & Reference Control (Housekeeping Gene) \\
\hline
\end{tabular}

reverse primers in a total volume of $20 \mu \mathrm{L}$. The cycling conditions were as follows: an initial incubation of $95^{\circ} \mathrm{C}$ for $5 \mathrm{~min}$ and then 45 cycles for Oct-4, Sox2, GAPDH, and 40 cycles for Nanog of $95^{\circ} \mathrm{C}$ for $30 \mathrm{~s}, 55^{\circ} \mathrm{C}$ for $30 \mathrm{~s}$ and $72^{\circ} \mathrm{C}$ for $30 \mathrm{~s}$ during which the fluorescence data were collected. Following amplification, a dissociation protocol was performed to provide evidence for a single reaction product. The threshold cycle $(\mathrm{Ct})$ value was calculated as the cycle where the fluorescence of the sample exceeded a threshold level. A no-template control of nuclease-free water was included in each run. All PCR reactions were studied in triplicate.

\subsection{Data Analysis}

The PCR efficiencies (E) were evaluated by 2 -fold dilution series of cDNAs (1 - 1:64 dilution) for each pair of primers including the reference gene (GAPDH) by using a cDNA pool obtained from all of the two and eight week old samples to ensure no inhibitory component was present in the samples. A graph of threshold cycle $(\mathrm{Ct})$ versus relative $\log _{2}$ copy number of the calibration sample from the dilution series was produced and the reaction efficiency was determined for each primer set by using the slope of this graph $\left(E=2^{(-1 / \text { slop })}\right)$ and percent efficiencies of the each primer pair was found to be higher than $98 \%$. No inhibitory effect was observed in amplifycation efficiencies $(E=2.0)$. Accordingly, $2^{-\Delta \Delta \mathrm{Ct}}$ method was used for the evaluation of the real-time RT-PCR results. The statistical analyses were performed using SPSS 15.0 software. The significance of the gene expression profiles between two and eight week old samples were tested with Student's t-test and p values smaller than 0.05 $(p<0.05)$ were considered as statistically significant.

\subsection{Immunohistochemistry}

Frozen ovary samples were cut in a series of $8 \mu \mathrm{m}$ sections by using Shandon cryotome cryostat (Thermo Scientific, USA) and transferred on to poly-l-Lysinecoated slides to prevent detachment of the sample sections from the slides. Sections were fixed at room temperature for $5 \mathrm{~min}$ with pre-cooled pure acetone. Fixed sections were rinsed in $1 \mathrm{X}$ Phosphate Buffered
Saline (PBS) three times, for five min each and incubated in blocking solution (1X PBS, 5\% Bovine Serum Albumin (BSA)) (Sigma, USA) and 0.5\% Triton-X100 (Sigma, Germany) for $30 \mathrm{~min}$. After blocking, sections were incubated overnight with primary antibody specific to Oct-4 (1:200, ab18976; Abcam, USA), Nanog (1:500, ab80892; Abcam, USA) and Sox2 (1:200, ab59776; Abcam, USA) at $4^{\circ} \mathrm{C}$. Sections were rinsed with $1 \mathrm{X}$ PBST (0.05\% Tween 20; Sigma, Germany) three times, for five min each and incubated with Alexa Fluor 594 goat anti-rabbit IgG (1:1000, A-11037; Invitrogen, USA) as secondary antibody at room temperature for an hour. All the antibodies were diluted in $1 \mathrm{X}$ PBS, $\mathrm{pH} 7.4,5 \%$ BSA and $0.5 \%$ Triton-X100. After incubating with secondary antibody, sections were rinsed in 1X PBST for five min for three times and sections were mounted with Antifade Vectashield mounting medium containing 4',6diamidino-2-phenylindole (DAPI; Vector Laboratories, Burlingame, CA) and visualized by using Carl Zeiss Axio Imager M1 microscope (Carl Zeiss MicroImaging, Inc., Thornwood, NY).

\section{RESULTS}

\subsection{Real Time RT-PCR}

The expression profiles of the three well known stem cell markers were elucidated in ovary samples obtained from two and eight-week-old mice in this study by qRT-PCR. Each of the markers, Oct-4, Nanog and Sox 2 were found to be expressed in both of the tissue types and Oct- 4 was found to be abundantly expressed compared to the other genes of interest (Figure 1).

The results of the qRT-PCR analysis showed that the expression of the Oct-4 and Nanog genes were signifycantly differentiated between two and eight weeks-old (Oct- $4 ; p=0.05$, Nanog; $p=0.01$ ) ovary samples. Oct-4 expression was found to be 1.8 fold upregulated in the samples obtained from two-week-old mice compared to the ones which are eight-week-old. On the contrary, Nanog expression was 1.93 fold downregulated in twoweek-old samples (Figures 1(a) and (b)). On the other hand, the difference in the expression levels of Sox 2 between two age groups (Figure 1(c)) were not statistically 
remarkable (t-test; $\mathrm{p}=0.14)$.

\subsection{Immunohistochemistry}

The immunohistochemistry results showed that Oct-4 and Sox2 proteins were ubiquitously expressed in the ovary; the expressions of which were observed in the cytoplasm of granulose cells, oocytes and theca cells and the ovarian epithelial cells (Figures 2 and 3). Nanog protein expression was observed only in nucleus of the oocytes

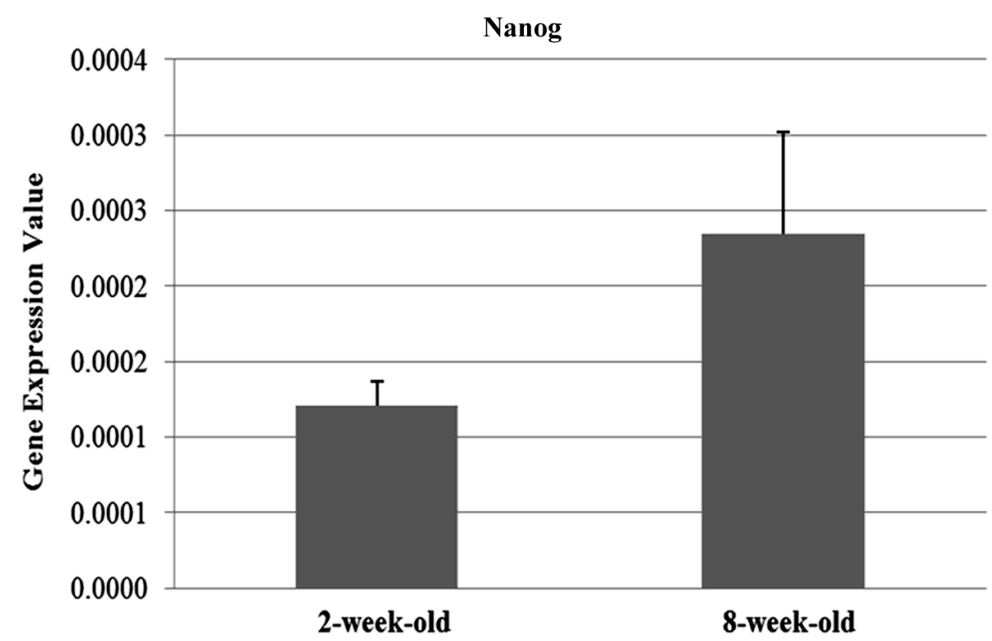

(a)

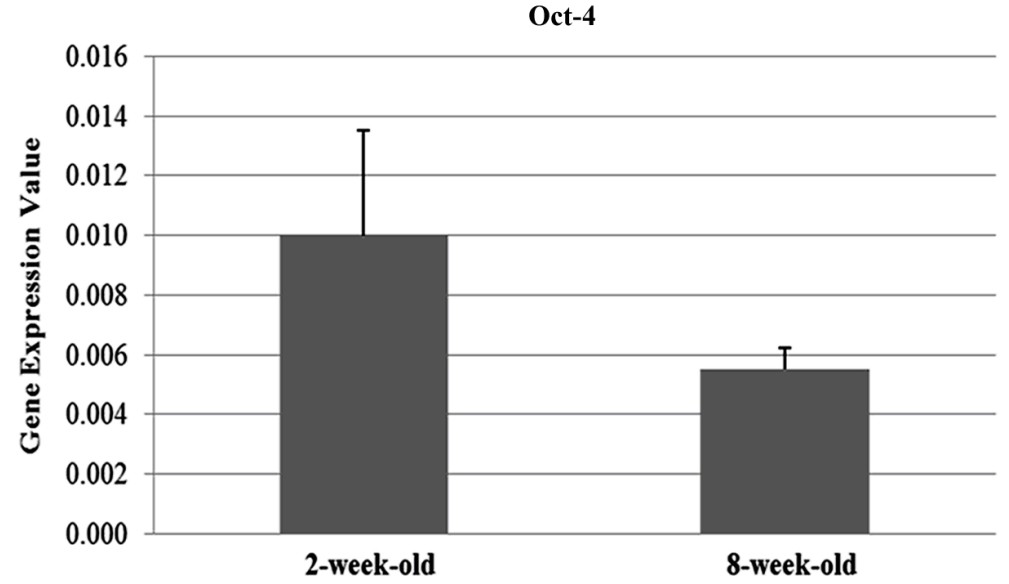

(b)

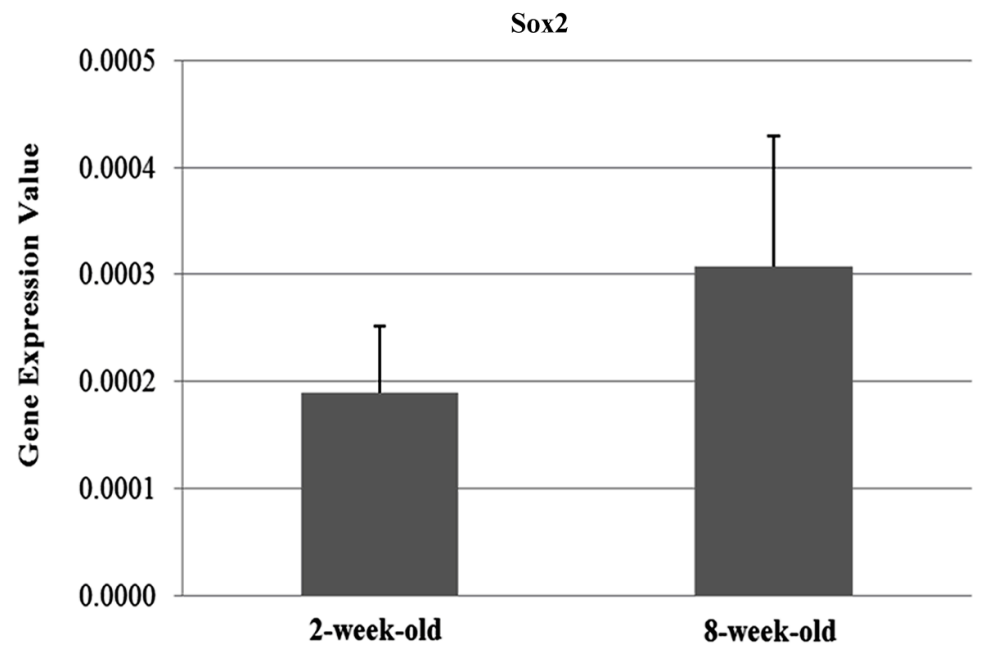

(c) 


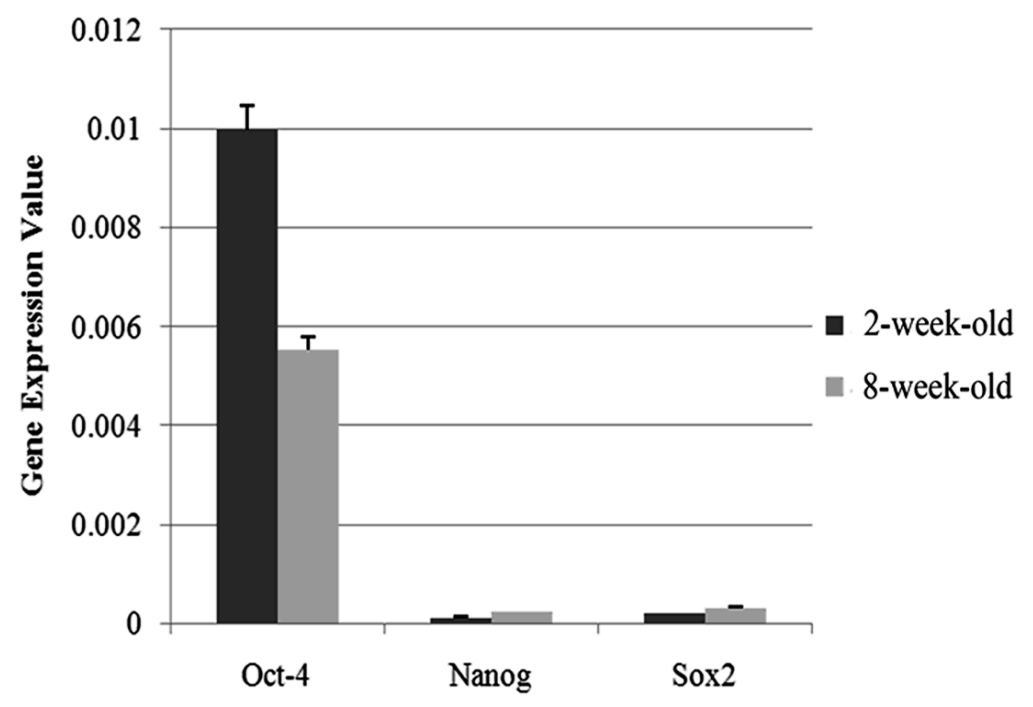

(d)

Figure 1. Graphics of Real Time PCR results in 2-week-old and 8-week-old samples. (a) Expression of Nanog were significantly differentiated between two and eight weeks-old $(\mathrm{p}=0.01)$ ovary samples and Nanog expression was 1.93 fold downregulated in two-week-old samples; (b) Expression of the Oct-4 were significantly differentiated between two and eight weeks-old $(\mathrm{p}=0.05)$ ovary samples and Oct-4 expression was found to be 1.8 fold upregulated in the samples obtained from two-weekold mice compared to the ones which are eight-week-old; (c) The difference in the expression levels of Sox 2 between two age groups were not statistically remarkable $(p=0.14)$; (d) Oct- 4 was found to be abundantly expressed compared to the other genes of interest.

(Figures 2 and 3(a)) and intensity of fluorescent signal was higher in eight weeks samples compared to the ones in two-week-old ones, which coincide with the qRT-PCR data.

\section{DISCUSSION}

In female primordial germ cells, Oct-4 is repressed by the beginning of meiotic prophase I and is then re-expressed after birth, coincident with the growth phase of oocytes. Oct-4 expression was demonstrated by RT-PCR in unfertilized oocytes and this protein was observed by immunohistochemistry in the cytoplasm of oocytes [13]. During oocyte development, Oct-4 protein have been observed in SN (surrounded nucleolus) oocytes but not in NSN (not surrounded nucleolus) oocytes and during oocyte growth, this protein has a tendency to surrounded oocyte nucleus and settle into cytoplasm [14]. Concordant with the results of above studies, we identified Oct4 expression in both age group samples. Furthermore, by Real Time-PCR and statistical analysis, we observed that Oct-4 expression in two week samples are higher than eight weeks. In addition, the presence of Oct-4 protein in both age groups was detected in the cytoplasm of ovarian epithelial cells, granulosa cells, oocytes and techa cells according to immuhistochemistry results.

In this study expression of Sox 2 was demonstrated in both age groups by Real Time-PCR. In addition we observed presence of Sox 2 protein in cytoplasm of ovarian epithelial cells, granulosa cells, techa cells and rim of oocytes nucleus and cytoplasm. According to another study, immunocytochemistry on adult mice ovaries disclosed high levels of Sox 2 protein in growing and mature oocytes, initially settled into the cytoplasm, and in some surrounding stromal cells [15].

In late oogenesis, analyses of ovaries collected from eight week adult mice with or without hormone stimulation by use of PMSG (pregnant mare's serum gonadotropin) identified that non-growing and growing oocytes were Nanog-negative [16]. In contrast to this research, we demonstrated expression of Nanog in all samples by qRT-PCR. In another study, low levels of Nanog expression were detected in many adult tissues by RT-PCR [17]. Furthermore, in our study, by using immunohistochemistry, presence of Nanog protein in both age groups was shown in the nuclei of oocytes. Our research is the first study that identified presence and location of Nanog protein in adult mouse ovaries and the first study that analyzed possible differences between Oct-4, Nanog and Sox 2 expression levels in pre-puberty and adult mouse 

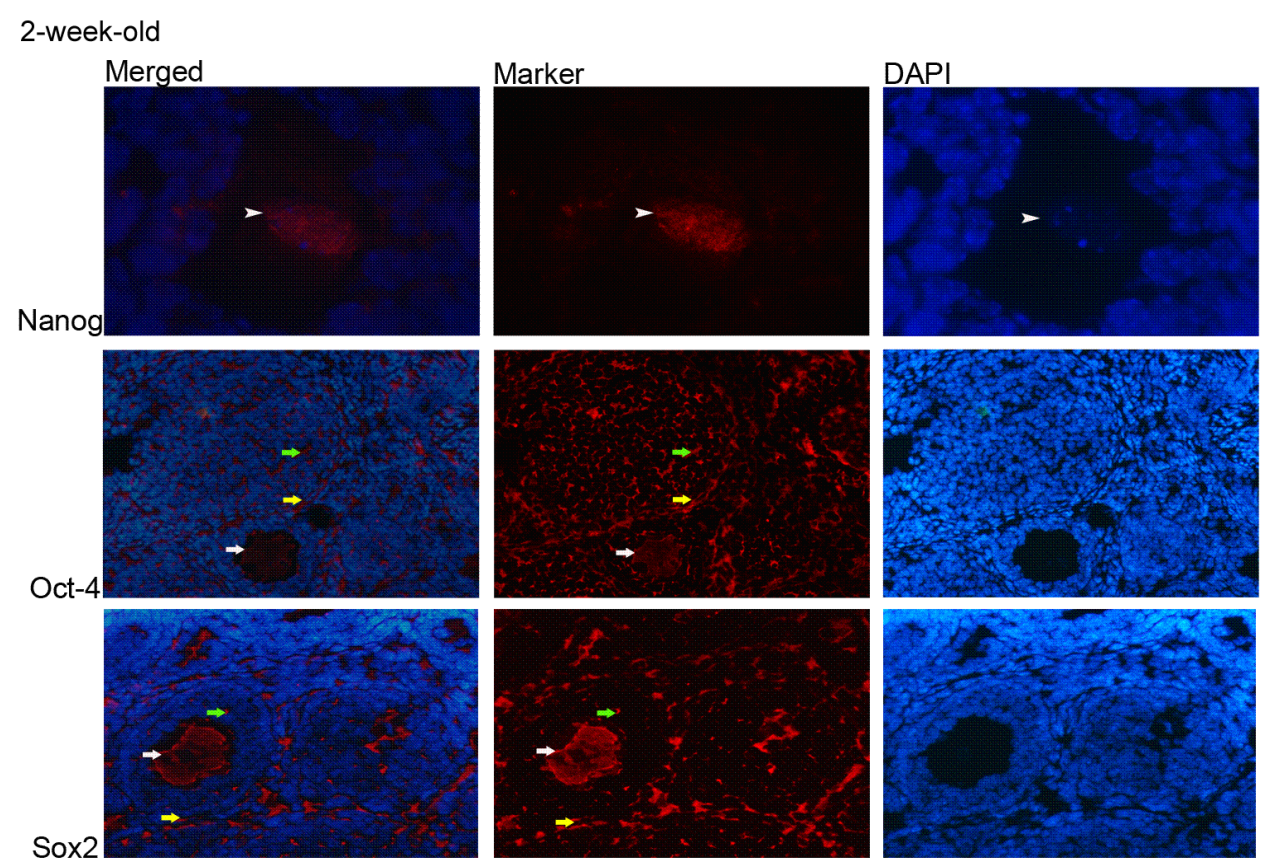

(a)
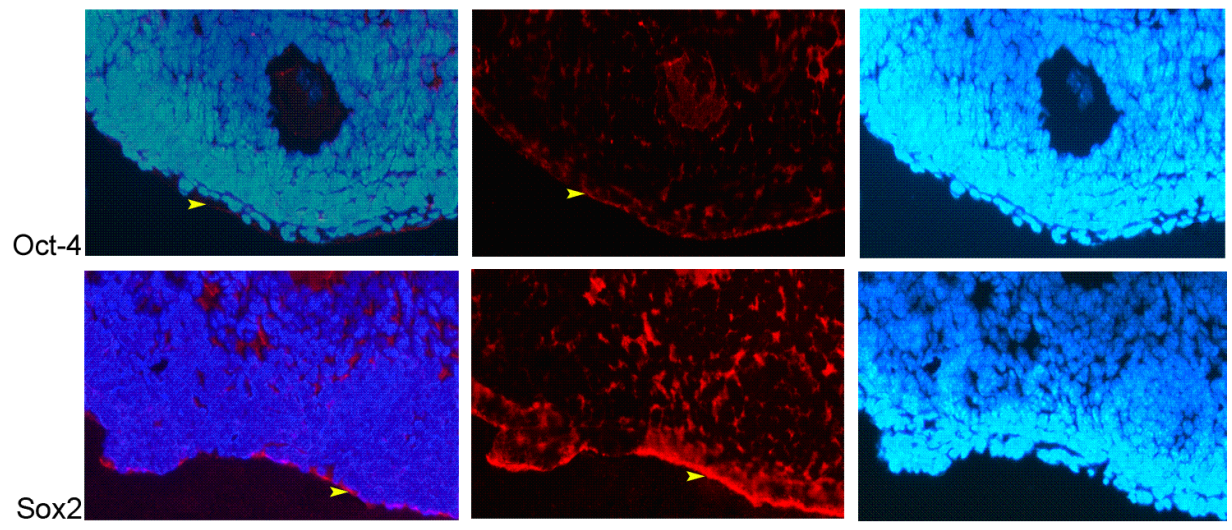

(b)

Figure 2. Expression of Nanog, Oct-4 and Sox 2 proteins in 2-week-old ovaries. (a) Nanog; nucleus of oocyte (white arrowhead) (100×), Oct-4 and Sox2; cytoplasm of granulosa cells (green arrow), theca cells (yellow arrow), and oocyte (white arrow) (20×); (b) Oct-4 and Sox2; cytoplasm of epithelial cells (yellow arrowhead) $(20 \times)$.

ovaries by quantitive RT-PCR.

According to the results of Real Time-PCR, in twoweek-old samples, expression of Nanog gene was lower than eight weeks (this result corresponds with immunohistochemistry result that demonstrates higher intensity of fluorescent signal in eight week samples). High expression of Oct-4 causes suppression of Nanog [18] and we considered that in two-week-old samples compared with eight week one, high expression of Oct-4 resulted in downregulation of Nanog expression.

In this study, we observed presence of Oct-4, Nanog and Sox 2 at mRNA and protein levels in adult and prepubertal mouse ovaries. mRNAs of these markers were demonstrated by qRT-PCR and as a result of immuno- histochemical staining Nanog protein was manifested in the nucleus of oocyte, Oct-4 and Sox 2 proteins were observed in cytoplasm of oocyte, granulosa, theca and epithelial cells. However, because of transcriptional regulator function of Oct-4, Nanog and Sox2, they have to be in nucleus of cells, but in our research and some studies that carried out previously, Oct-4 and Sox 2 proteins were observed in the cytoplasm of adult ovary cells [13-15]. During localization of these proteins in the cytoplasm of cells, pluripotential capacity of these cells can be questionable [13]. Nevertheless, depending on the cellular stimulation transcription factors by means of the Nuclear Localization Sequence or NLS (short amino acid sequences) make a transition from cytoplasm to nucleus 
8-week-old
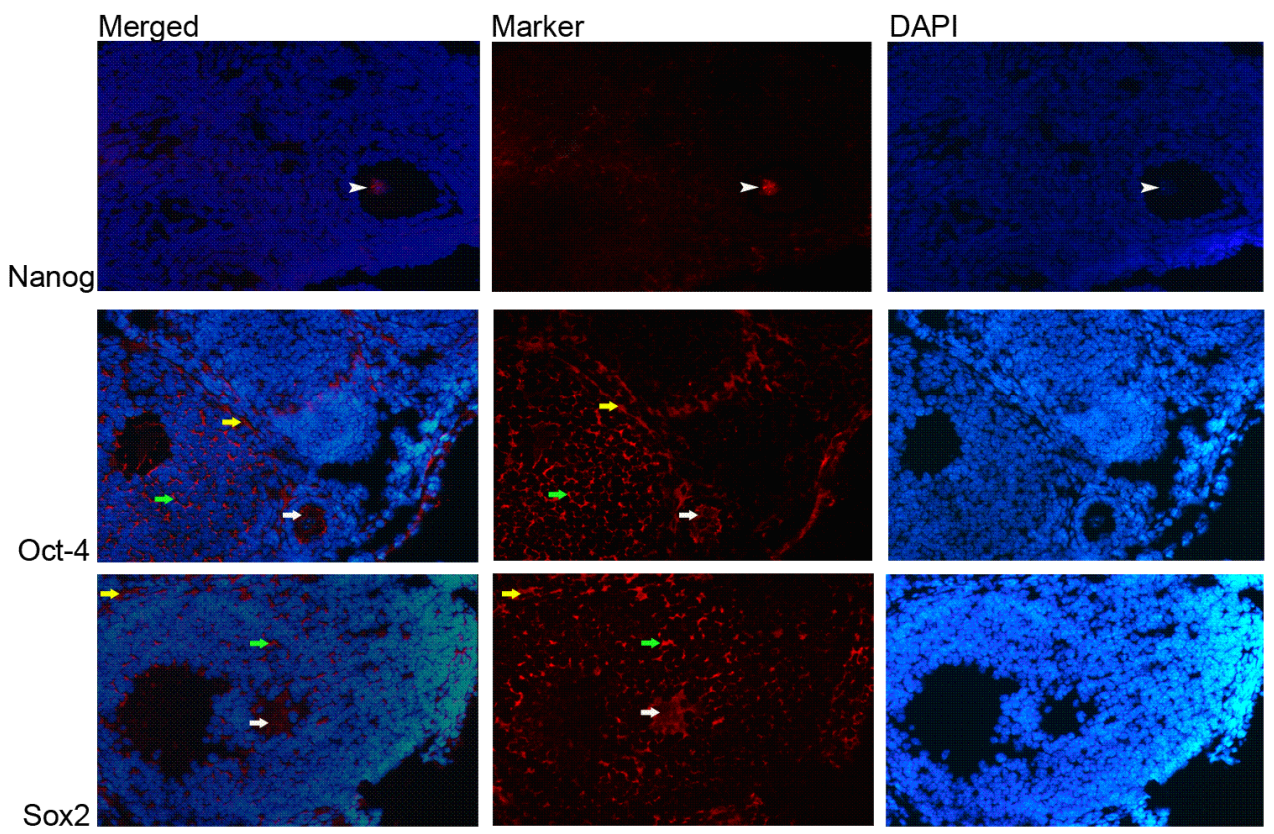

(a)
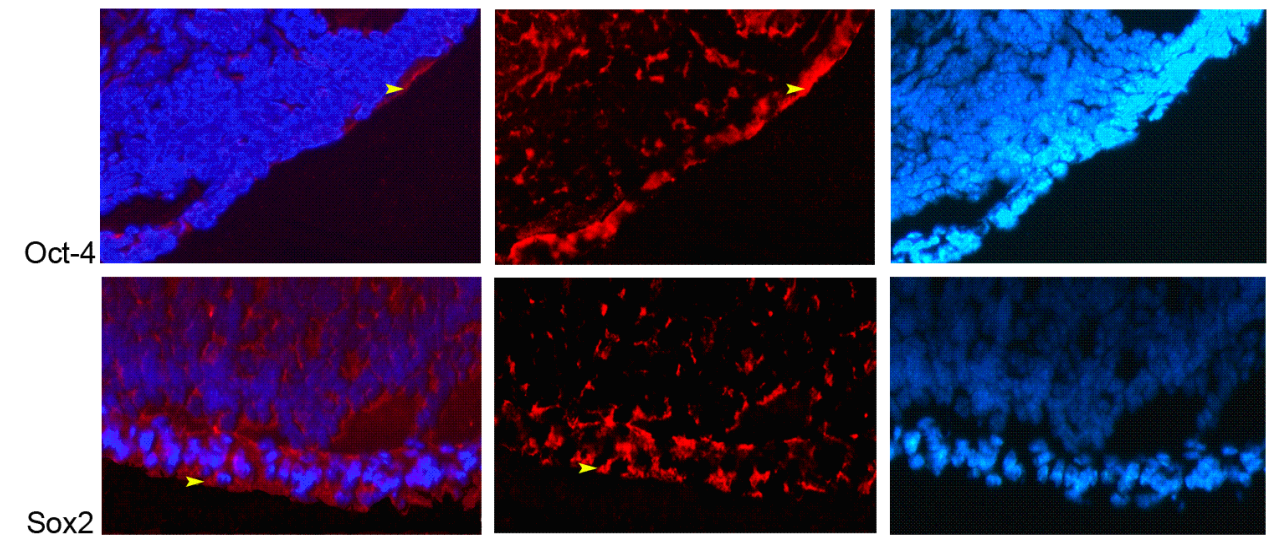

(b)

Figure 3. Expression of Nanog, Oct-4 and Sox 2 proteins in 8-week-old ovaeies. (a) Nanog; nucleus of oocyte (white arrowhead), Oct-4 and Sox2; cytoplasm of granulosa cells (green arrow), theca cells (yellow arrow), and oocyte (white arrow) (20×); (b) Oct-4 and Sox2; cytoplasm of epithelial cells (yellow arrowhead) $(20 \times)$.

and through the Nuclear Export Sequence or NES passing in the opposite direction [19]. Additionally, some studies demonstrated the differentiation of a number of cells from adult ovarian stem cells. For instance, Bokovsky and colleagues (2009) observed the differentiation of oocyte, fibroblast, neural and epithelial cells from adult ovarian stem cells [20].

Consequently, the ESC markers Oct-4, Sox2, and Nanog, were shown to be present at mRNA and protein levels in pre-puberty (two-week-old) and adult (eightweek-old) mice ovaries. In conclusion, they have the cells that contain the characteristics of pluripotent stem cells capacities.

\section{ACKNOWLEDGEMENTS}

This work was supported and funded by the TUBITAK-BIDEB (program 2215) and Biotechnology Institute of Ankara University.

\section{REFERENCES}

[1] Johnson, J., Canning, J., Kaneko, T., Pru, J.K. and Tilly, J.L. (2004) Germline stem cells and follicular renewal in the postnatal mammalian ovary. Nature, 428, 145-150. doi:10.1038/nature02316

[2] Bukovsky, A., Svetlikova, M. and Caudle, M.R. (2005) Oogenesis in cultures derived from adult human ovaries. Reproductive Biology and Endocrinology, 3, 17. 


\section{doi:10.1186/1477-7827-3-17}

[3] Virant-Klun, I., Zech, N., Rozman, P., Vogler, A., Cvjeticanin, B., Klemenc, P., Malicev, E. and Meden-Vrtovec, H. (2008) Putative stem cells with an embryonic character isolated from the ovarian surface epithelium of women with no naturally present follicles and oocytes. Differentiation, 76, 843-856. doi:10.1111/j.1432-0436.2008.00268.x

[4] Honda, A., Hirose, M., Hara, K., Matoba, S., Inoue, K., Miki, H., Hiura, H., Kanatsu-Shinohara, M., Kanai, Y. and Kono, T. (2007) Isolation, characterization, and in vitro and in vivo differentiation of putative thecal stem cells. Proceedings of the National Academy of Sciences USA, 104, 12389-12394. doi:10.1073/pnas.0703787104

[5] Liu, Y., Wu, C., Lyu, Q., Yang, D., Albertini, D.F., Keefe, D.L. and Liu, L. (2007) Germline stem cells and neooogenesis in the adult human ovary. Developmental Biology, 306, 112-120. doi:10.1016/j.ydbio.2007.03.006

[6] Boyer, L.A., Mathur, D. and Jaenisch, R. (2006) Molecular control of pluripotency. Current Opinion in Genetics \& Development, 16, 455-462. doi:10.1016/j.gde.2006.08.009

[7] Chambers, I., Colby, D., Robertson, M., Nichols, J., Lee, S., Tweedie, S. and Smith, A.G. (2003) Functional expression cloning of Nanog, a pluripotency sustaining factor in embryonic stem cells. Cell, 113, 643-655. doi:10.1016/S0092-8674(03)00392-1

[8] Mitsui, K., Tokuzawa, Y., Itoh, H., Segawa, K., Murakami, M., Takahashi, K., Maruyama, M., Maeda, M. and Yamanaka, S. (2003) The homeoprotein Nanog is required for maintenance of pluripotency in mouse epiblast and ES cells. Cell, 113, 631-642. doi:10.1016/S0092-8674(03)00393-3

[9] Boyer, L.A., Lee, T.I., Cole, M.F., Johnstone, S.E., Levine, S.S., Zucker, J.P., Guenther, M.G., Kumar, R.M., Murray, H.L., Jenner, R.G., Gifford, D.K., Melton, D.A., Jaenisch, R. and Young R.A. (2005) Core transcriptional regulatory circuitry in human embryonic stem cells. Cell, 122, 947-956. doi:10.1016/j.cell.2005.08.020

[10] Rodda, D.J., Chew, J., Lim, L.H., Loh, Y.H., Wang, B., Ng, H.H. and Robson, P. (2005) Transcriptional Regulation of Nanog by OCT4 and SOX2. Journal of Biological Chemistry, 280, 24731-24737. doi:10.1074/jbc.M502573200

[11] Masui, S., Nakatake, Y., Toyooka, Y., Shimosato, D., Yagi, R., Takahashi, K., Okochi, H., Okuda, A., Matoba, R., Sharov, A.A., Ko, M.S. and Niwa, H. (2007) Pluripotency governed by Sox 2 via regulation of Oct 3/4 expres- sion in mouse embryonic stem cells. Nature Cell Biology, 9, 625-635. doi:10.1038/ncb1589

[12] Zou, K., Yuan, Z., Yang, Z., Luo, H., Sun, K., Zhou, L., Xiang, J., Shi, L., Yu, Q., Zhang, Y., Hou, R. and Wu, J. (2009) Production of offspring from a germline stem cell line derived from neonatal ovaries. Nature Cell Biology, 11, 631-636. doi:10.1038/ncb1869

[13] Cauffman, G., Van de Velde, H., Liebaers, I. and Van Steirteghem, A. (2005) Oct-4 mRNA and protein expression during human preimplantation development. Molecular Human Reproduction, 11, 173-181. doi:10.1093/molehr/gah155

[14] Zuccotti, M., Merico, V., Sacchi, L., Bellone, M., Brink, T.C., Stefanelli, M., Redi, C.A., Bellazzi, R., Adjaye, J. and Garagna, S. (2009) Oct-4 regulates the expression of Stella and Foxj2 at the Nanog locus: implications for the developmental competence of mouse oocytes. Human Reproduction, 24, 2225-2237. doi:10.1093/humrep/dep191

[15] Avilion, A.A., Nicolis, S.K., Pevny, L.H., Perez, L., Vivian, N. and Lovell-Badge, R. (2003) Multipotent cell lineages in early mouse development depend on SOX2 function. Genes \& Development, 17, 126-140. doi:10.1101/gad.224503

[16] Yamaguchi, S., Kimura, H., Tada, M., Nakatsuji, N. and Tada, T. (2005) Nanog expression in mouse germ cell development. Gene Expression Patterns, 5, 639-646. doi:10.1016/j.modgep.2005.03.001

[17] Hart, A.H., Hartley, L., Ibrahim, M. and Robb, L. (2004) Identification, cloning and expression analysis of the pluripotency promoting Nanog genes in mouse and human. Developmental Dynamics, 230, 187-198. doi:10.1002/dvdy.20034

[18] Niwa, H., Miyazaki, J. and Smith, A.G. (2000) Quantitative expression of Oct $3 / 4$ defines differentiation, dedifferentiation or self-renewal of ES cells. Nature Genetics, 24, 372-276. doi:10.1038/74199

[19] Whiteside, S.T. and Goodbourn, S. (1993) Signal transduction and nuclear targeting: regulation of transcription factor activity by subcellular localisation. Journal of Cell Science, 104, 949-955.

[20] Bukovsky, A., Caudle, M.R., Virant-Klun, I., Gupta, S.K., Dominguez, R., Svetlikova, M. and Xu, F. (2009) Immune physiology and oogenesis in fetal and adult humans, ovarian infertility, and totipotency of adult ovarian stem cells. Birth Defects Research Part C, 87, 64-89. 


\section{ABBREVIATIONS}

BSA: Bovine Serum Albumin

DAPI: 4',6-Diamidino-2-Phenylindole

ESC: Embryonic Stem Cell

GAPDH: Glyceraldehyde-3-Phosphate Dehydrogenase GFP: Green Fluorescent Protein

GSCs: Germline Stem Cells

OCT-4: Octamer-Binding Transcription Factor 4

OSCs: Ovarian Stem Cells

OSE: Ovarian Surface Epithelium
PBS: Phosphate Buffered Saline

PCNA: Proliferating Cell Nuclear Antigen

PhR: Phenol Red

RT-PCR: Reverse Transcription Polymerase Chain Reaction

SCP: Synaptonemal Complex Protein

Sox2: Sex Determining Region Y Box 2

SSEA: Stage-Specific Embryonic Antigen

TERT: Telomerase Reverse Transcriptase

ZP2: Zona Pellucida Sperm-Binding Protein 2 